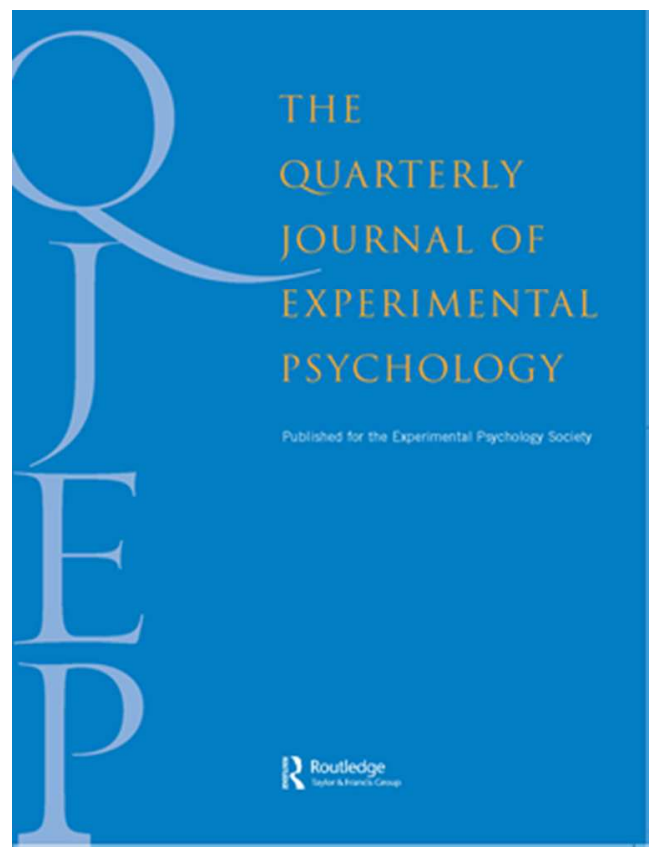

\title{
Where do dialectal effects on speech processing come from? Evidence from a cross-dialect investigation
}

\begin{tabular}{|r|l|}
\hline Journal: & Quarterly Journal of Experimental Psychology \\
\hline Manuscript ID: & Draft \\
\hline Manuscript Type: & Standard Article \\
\hline Complete List of Authors: & $\begin{array}{l}\text { Larraza, Saioa; CNRS. Laboratoire Psychologie de la Perception, ; BCBL. } \\
\text { Basque Center on Cognition, Brain and Language, } \\
\text { Samuel, Arthur; BCBL. Basque Center on Cognition, Brain and Language, ; } \\
\text { IKERBASQUE, Basque Foundation for Science, ; Stony Brook University, } \\
\text { Department of Psychology } \\
\text { Oñederra, Miren Lourdes; University of the Basque Country, Department of } \\
\text { Linguistics and Basque Studies }\end{array}$ \\
\hline Keywords: & $\begin{array}{l}\text { Cross-dialect variation, accented speech, speech perception, spoken word } \\
\text { recognition, very early and proficient bilinguals }\end{array}$ \\
\hline \hline
\end{tabular}




\title{
Where do dialectal effects on speech processing come from? Evidence from a cross-dialect investigation
}

\author{
Saioa Larraza \\ CNRS. Laboratoire Psychologie de la Perception, UMR 8158 \\ BCBL. Basque Center on Cognition, Brain and Language. Donostia-San Sebastian, Spain \\ Arthur G. Samuel \\ BCBL. Basque Center on Cognition, Brain and Language. Donostia-San Sebastian, Spain \\ IKERBASQUE, Basque Foundation for Science \\ Department of Psychology, Stony Brook University \\ Miren Lourdes Oñederra \\ University of the Basque Country, Vitoria-Gasteiz, Spain \\ Department of Linguistics and Basque Studies
}

\author{
Corresponding author: \\ Saioa Larraza \\ Laboratoire Psychologie de la Perception, UMR 8158 \\ CNRS - Université Paris Descartes \\ 45, Rues des Saints-Pères \\ 75006 Paris \\ France \\ Tel. +33(0)1.42.86.43.14 \\ Email: saioa.larraza@parisdescartes.fr
}

\section{Acknowledgments}

This study was conducted with the support of the PSI 2010-17781 grant from the Spanish Goverment (MINECO). We want to especially thank Alazne Alegre for all her help recording the stimuli and running the experiments. 


\begin{abstract}
Accented speech has been seen as an additional impediment for speech processing; it usually adds linguistic and cognitive load to the listener's task. In the current study we analyze where the processing costs of regional dialects come from, a question that has not been answered yet. We quantify the proficiency of Basque-Spanish bilinguals who have different native dialects of Basque on many dimensions and test for costs at each of three levels of processing phonemic discrimination, word recognition, and semantic processing. The ability to discriminate a dialect-specific contrast is affected by a bilingual's linguistic background less than lexical access is, and an individual's difficulty in lexical access is correlated with basic discrimination problems. Once lexical access is achieved, dialectal variation has little impact on post-access semantic processing.
\end{abstract}

Key-words

Cross-dialect variation, accented speech, speech perception, spoken word recognition, very early and proficient bilinguals. 


\section{Introduction}

To a person born and raised in Dallas, the speech of a native New Yorker sounds rather odd. Conversely, a Southern accent is quite marked for the native New Yorker. And, a native of Chicago will notice odd properties in the speech of both of these others. The differences reflect the impact of dialects of American English. The same kind of dialectal clash is experienced by individuals from Paris versus Marseille, given the quite different dialects of French in these two places. In the current study, our focus will be on such regional accents, as they constitute a natural source of variation in any spoken language. Our test case involves dialectal variation in Basque, which illustrates that one does not need to travel almost a thousand kilometers to find these differences - regions within a hundred kilometers of each other can show substantial dialectal variation.

Although listeners usually succeed in adjusting to variation produced by another user of their own language (e.g. Clopper \& Pisoni, 2004), a growing body of evidence shows that perceptual difficulties can arise among native listeners for phonemic contrasts that do not belong to their regional dialect (e.g., Conrey, Potts, \& Niedzielski, 2005; Dufour, Brunellière, \& Nguyen, 2013; Ingram \& Park, 1997). Hence, it is necessary to make an explicit distinction between the native language and the native dialect. Most prior dialectal studies have been designed to show that regional accents have costs on spoken word recognition (Deelman $\&$ Connine, 2001; Floccia, Goslin, Girard, \& Konopczynski, 2006; Gaskell \& Marslen-Wilson, 1996; Gow, 2001, 2003; Janson \& Schulman, 1983; LoCasto \& Connine, 2002; McLennan, Luce, \& Charles-Luce, 2003; Mitterer \& Blomert, 2003; Scott \& Cutler, 1984). This is an important finding, but it remains to be determined where these dialectal effects come from. This is the goal of the current study: We seek to localize any dialectal effects by testing how crossdialect variation influences speech processing at different levels of representation. Prior work has not examined how phonemic discrimination capacity might contrast with lexical activation (at either the word form or semantic level) in cases of cross-dialect variation. Such an analysis is fundamental in order to fully understand the representation of dialectal variants.

By focusing on dialects of Basque, our study also allows us to examine how regional dialects are perceived by bilinguals - all of the participants in our study were highly fluent, very early Basque-Spanish bilinguals. A great deal of recent research has shown that it is necessary to 
consider the differences and commonalities between bilinguals' and monolinguals' speech processing. Our study thus tests whether bilinguals' linguistic experience affects the way they adjust to regional accents, as it does in monolinguals (e.g., Conrey et al., 2005; Dufour et al., 2013; Floccia, Butler, Goslin, \& Ellis, 2009; Floccia et al., 2006).

The observed processing costs for non-native dialects have varied quite a bit across different studies. In some studies that tested vocalic contrasts, listeners showed no perceptual difficulties with the non-native dialect (Cutler, Smits, \& Cooper, 2005; Dufour, Nguyen, \& Frauenfelder, 2007). In contrast, Conrey et al. (2005) found that for dialects with merged phonemic contrasts that remain contrastive in other varieties of same the language, listeners of the merged dialect show poorer discrimination of the critical contrast than of control contrasts shared by the two dialects. More surprisingly, the merged contrast seems to affect the perception of listeners of the unmerged dialect as well, with worse performance on the merged contrasts than on control contrasts. This tendency has been interpreted as the effect of exposure to speakers of the merged dialect (Brunellière, Dufour, Nguyen, \& Frauenfelder, 2009; Conrey et al., 2005). Most of the studies analyzing perceptual accommodation to a merged contrast by different groups of listeners have looked at vocalic contrasts. The fact that vowels are perceived less categorically than consonants might have influenced the results - effects have been found in both directions, either facilitating or hindering discrimination. In the current study we investigate the source of these effects, using a consonant contrast that differs across two dialects of Basque.

\section{$\underline{\text { Phonemic contrast of interest }}$}

Standard Basque includes two voiceless fricatives that contrast in their active place of articulation: apical alveolar/s/vs. laminal alveolar/s/. This is one-phonetic-feature contrast that makes minimal pairs in Standard Basque but that does not exist in Castilian Spanish, which only has the apical /s/ sound. The apical-laminal contrast of Standard Basque also is absent in the Western dialect of Basque because the Western dialect merges the sibilant fricatives' contrast in favor of the apical sound $(/ \mathrm{s} />/ \mathrm{S} /)$. Although it has additional distinctive morphological and phonological characteristics that make it distinguishable from other Basque dialects, for the purposes of this study we will only focus on the fricative merger. "Standard" Basque is meant to 
cover all non-merging Basque dialects. In Table 1 we present the phonemic distribution of the fricatives of interest in Castilian Spanish and in the two dialects of Basque.

INSERT TABLE 1 HERE

It is important to know that there is also another source of variation that results in the same kind of apical articulation of the laminal fricative: mispronunciations by native speakers of Spanish who learn Basque. These speakers often mispronounce the laminal sound (not part of their native inventory) as apical (present in their native inventory). Thus, both accents - the Western accent and Spanish-accented Basque - merge the alveolar contrast into the same sound, but the context and additional morphophonological characteristics of the input inform the listener about the accent they are hearing. In the current study, "accented speech" refers to either Western vernacular pronunciation or Spanish-influenced pronunciation, which in both cases involves the change of $/ \mathrm{s} /$ to $/ \mathrm{S} /$.

We (Larraza, Samuel, \& Oñederra, submitted) recently investigated how Basque bilinguals perceive syllables and words that contain this critical Basque contrast, examining effects of the age at which a bilingual learned Standard Basque, and the effect of having either Spanish or French as a first language. In the current study, we use the same set of tasks as before, but we test Spanish-Basque very early bilinguals who are native speakers of the Western dialect. We report the results for these native Western speakers, together with results from the simultaneous Spanish-Basque bilinguals from the previous study. This provides a direct comparison of two groups of very early Spanish-Basque bilinguals who differ in their native dialect of Basque - Standard versus Western.

Best's Perceptual Assimilation Model, PAM (Best, 1995; Best \& Tyler, 2007) and Flege's Speech Learning Model, SLM (Flege, 1995), primarily proposed in the context of second-language speech perception, can be used to predict performance by bilinguals with different regional dialects. Even though PAM focuses on the invariant articulatory gestures that 
listeners extract from the speech signal, and SLM states that listeners form categories from acoustic-phonetic cues, both models predict that listeners should be able to discriminate sounds that are not considered to be equivalent to native phonemes. For the case under study here, both PAM and SLM would predict that Western speakers should have some ability to distinguish the critical sounds, to the extent that they perceive any of the acoustic properties of the laminal/s/ sound. Greater experience with the non-native dialect will result in better attuned perception, enabling more precise discrimination of the non-native sound.

Stampe’s Natural Phonology Theory, NP (Stampe, 1979) makes a similar prediction. According to NP, implicit phonetic forces in human vocalization and perception govern the sound patterns of languages, "naturally" adjusting our phonological intentions to our phonetic capacities (Donegan \& Stampe, 1979). NP explains the sound learning process as the suppression of natural phonetic constraints. Overcoming these implicit constraints gives a speaker the capacity to distinguish (both in perception and production) sounds of the language. Phonological acquisition is thus interpreted by NP in terms of inhibition of natural mental processes. In line with PAM and SLM, NP predicts that the phonological processes of the native language or dialect will affect later language learning and processing, in both perception and production. That is, unsuppressed phonetic constraints will influence the learning of non-native sounds and sequences. For the phonemic contrast of interest (present in Standard Basque but not in the Western dialect and Spanish), it remains to be seen if Western speakers still have the natural phonetic constraint active, or if instead they are able to inhibit it thanks to their contact with Standard Basque. If the latter is true, Western speakers will successfully discriminate the critical phonemic contrast. But if the former is true, very poor discrimination would be expected. Basque bilinguals' language experience will be a determinant of the degree of difficulty and/or success in inhibiting L1 processes (Larraza, 2009).

Note that for all three theories, the most straightforward predictions are for performance on a basic discrimination task: Should a given listener be expected to succeed in discriminating the apical and laminal variants? Normal language use, of course, does not involve such basic discrimination - it is grounded in recognizing the words that a person hears. Therefore, in order to understand how dialectal variation affects word recognition, in our previous study and in the current one we had subjects complete three experiments that targeted different levels of representation. An AXB discrimination task probes basic phonetic-phonological discrimination 
performance for which models like PAM, SLM, and NP make predictions. An auditory lexical decision task measures dialectal effects in lexical access, and an auditory semantic priming task tests whether there are any post-lexical access effects of dialectal variation. Conducting these experiments as a set allows us to determine where any costs arise. The experiments were run within-subjects so that we can test whether difficulties at one level of processing (e.g., basic discrimination of a contrast) correlate with performance at other levels (e.g., lexical access). All participants did the semantic priming task first, then the AXB task, with the lexical decision task run last to prevent listeners from becoming aware of the phonemic contrast of interest. For clarity of the exposition, we report the experiments in ascending order: (1) phonetic processing, (2) lexical access, and (3) semantic association. Full stimulus lists and procedural details beyond those reported here are provided in Larraza, Samuel, and Oñederra (submitted).

\section{Experiment 1: AXB Discrimination task}

Studies on phonemic discrimination of contrasts not present in a listener's native dialect reveal poorer discrimination by speakers of a merged dialect than native speakers of the nonmerger dialect (Brunellière et al., 2009; Dufour et al., 2013). Our first experiment will tell us how well Western speakers are able to distinguish the Basque fricative contrast that is not present in their own dialect, compared to speakers of Standard Basque for whom this is a native contrast. We predict that Western speakers will show difficulties distinguishing the /s/-/s/ contrast at a low, acoustic-phonetic level, given that this distinction is not part of their native inventory. However, based on what similar studies show (Cutler et al., 2005; Dufour et al., 2007), Western speakers may have some sensitivity to the apical-laminal distinction due to its presence in their linguistic environment (TV, radio, school, interactions with Standard speakers, etc.), where Standard Basque - and therefore, the /s/-/s/ contrast - is often used. Western speakers may be comparable to Spanish-Basque (L2) late bilinguals in terms of their difficulty in perceiving a non-native contrast (Larraza et al. submitted): For the former, the native dialect's pronunciation would limit performance, while for the latter the late age of acquisition of L2 reduces sensitivity to the contrast. 


\section{Method}

\section{Participants}

We tested two groups of Spanish-Basque bilinguals who were distinguished by their native dialect of Basque. There were 29 native speakers (20 female) of Standard Basque who learned both Spanish and Basque from birth (the Simultaneous Spanish-Basque group of Larraza et al., submitted). None of those Spanish-Basque simultaneous bilinguals had the Western dialect themselves, nor had they been extensively exposed to it. 26 native speakers ( 20 female, 6 male) of the Western dialect composed the second group. This group started learning Spanish on average at 4.1 years. All participants were 18 years of age or older, and spoke Basque very fluently (in a structured interview, their average Basque spoken proficiency was 4.7 on a fivepoint scale). On a daily basis, Standard speakers used Basque $38 \%$ of the time and Western speakers did so $65 \%$ of the time. All reported that they had normal hearing, and all received payment for their participation.

\section{Stimuli and Procedure}

On each trial, listeners heard three tokens. The first (A) and last (B) tokens were always phonetically different, and the middle token $(\mathrm{X})$ was always phonetically identical to either the first one, or the second one. The Inter Stimulus Interval (ISI) was 300ms, both between the first and second item, and between the second and third. The task was to decide whether the middle item matched the first sound (AAB) or the last sound (ABB). Subjects were instructed to press one button when the middle item matched the first sound, and a different button with when it matched the last sound. The labels " 1 " and " 3 " were shown on the left and right sides, respectively, of a computer monitor. The Inter Trial Interval (ITI) was 1000ms after the subject's response.

We only tested nonword stimuli - monosyllabic or disyllabic items. The critical sounds were embedded in different plausible phonetic contexts of Basque: \#_V, V_V, VC_V. An acoustic analysis of the critical sounds revealed significant differences in three measures of 
interest: the apical sound /s/ is shorter and louder than the laminal /s/ sound, and it has a lower spectral centroid (see Larraza et al. (submitted) for further details).

Participants listened to 80 critical trials ( 2 sounds $-/ \mathrm{s} /$ and /s/ - x 20 times each x 2 positions - $\mathrm{AAB}$ and $\mathrm{ABB}-$ ); half of the critical trials were monosyllabic and half were disyllabic. The two critical sounds appeared equally often in AAB and ABB trials. 160 control trials were included to provide a comparison to other single-feature contrasts. All the control phonemic contrasts were legal in Basque and Spanish (e.g., /m/-/n/, /p/-/b/, /t/-/d/, etc.). Each control trial appeared twice as well, once as $\mathrm{AAB}$ and once as $\mathrm{ABB}$.

There were two counterbalanced lists of 240 trials ( 80 critical, 160 control) that were identical, except for the voices included in each trial. Each trial presented items recorded by three different native speakers of Basque, where the " $X$ " item was always in the opposite gender of the "A" and "B" items (e.g., female1 - male - female2). This was done in order to force a categorical judgments from listeners, rather than a pure acoustic-phonetic one. All speakers clearly distinguished the critical sounds, according to a Basque native trained phonetician. Half of the participants were tested with each list. Trials for each listener were individually randomized. All stimuli were presented binaurally over Beyerdynamic DT 770 Pro Studio headphones at a comfortable listening level.

\section{Results and Discussion}

Missing responses (1.1\%) and trials with responses faster than $200 \mathrm{~ms}$ or slower than $2500 \mathrm{~ms}(1.8 \%)$ were not included in the analyses. Due to a software problem, data files were corrupted for some of the subjects, leaving 21 speakers (15 female) for the Standard Basque group; no files were lost for the Western speakers.

Analyses were conducted using the lme4 package (Bates, Maechler, Bolker, \& Walker, 2013) for linear mixed-effect models in $R$ ( $R$ Development Core Team, 2012). The intercept, the estimated regression coefficients (Estimate), standard error (SE) and t/Wald's z values resulting from the linear mixed-effect model analysis are reported for each comparison of interest. Current implementations of the lmer function do not provide p-values when models have both random slopes and intercepts. Thus, the t-values reported in the text are treated as approximations to $\mathrm{z}$, and any absolute value of $t$ greater than 2 was considered to be a significant difference. Both 
accuracy and RT were analyzed as the dependent variables. The fixed factors were Native Dialect (Standard versus Western), Condition (Critical versus Control pairs) and Position (AAB versus $\mathrm{ABB})$.

For this and for the following experiments, we built a series of models adding the fixed factors as well as their interactions incrementally by increasing the complexity of the randomeffects structure, as Barr, Levy, Scheepers, and Tily (2013) suggest. An initial analysis determined that List was not playing any role in the discrimination of the two sounds of interest, therefore we did not include it as a factor in the main analyses. Similarly, Position (AAB versus ABB) was only used to reduce error variance from the two factors of theoretical interest. Improved fit was assessed using the likelihood ratio test. Subsequently, we included by-subject and by-item random intercepts and random slopes, and the main effects of Native Dialect and Condition were assessed by testing how much the model fit increased when adding each of these factors individually. The base model included by-subjects and by-item random intercepts and random slopes, together with an interaction of Native Dialect by Condition among the fixed factors, given that it provided greater explanatory power. The reference level for the intercept was set to the Standard Basque group and control condition.

Accuracy: As the left side of Figure 1 shows, critical items (90\% accuracy) were harder to distinguish than control stimuli (97\%) for both dialect groups, leading to a significant effect of Condition (Intercept: 5.57, SE: 0.29, $\beta$ : -1.04, SE: 0.35, Wald's z: -2.94). Bilinguals who speak Standard Basque performed significantly better than Western speakers ( $\beta$ : -0.65 , SE: 0.32 , Wald's z: -2.07). Of particular importance to our main issue, this advantage was more pronounced when discriminating the critical contrast, resulting in a significant interaction of Native Dialect by Condition ( $\beta$ : -0.9, SE: 0.4, Wald's z: -2.24).

Response Times: Incorrect trials (5.04\%) were excluded from the reaction time analysis. In agreement with the accuracy results, critical sounds were not only harder to discriminate, they also generated longer reaction times $(781 \mathrm{~ms})$ than control $(689 \mathrm{~ms})$ contrasts, leading to a significant effect of Condition (Intercept: 671.37, SE: 21.47, $\beta: 59.18$, SE: 19.49, t: 3.04). Critical sounds slowed down the response times for the Western speakers more than for the Standard speakers, producing a significant interaction of Native Dialect by Condition ( $\beta$ : 80.26, SE: 27.01, t: 2.97). Thus, both the accuracy and the response time data show an additional cost for Western dialect speakers when the critical sounds had to be discriminated. 
In the Western dialect the contrast between the apical and laminal fricatives is merged; that was the motivation for contrasting this group with the Standard Basque-Spanish simultaneous group. The results of Experiment 1 show that the Western group performed significantly more poorly than the Standard group, a difference that was reflected in both accuracy and reaction time; there were clear native dialect effects for the critical sounds. Although $86 \%$ correct accuracy is very much better than chance, it is well below the near-perfect performance of the Standard Basque speakers. Moreover, this percentage should be considered in the context of the relatively easy AXB discrimination task, where sounds to be matched appear in isolation.

This effect of the regional dialect agrees with the predictions of Stampe's NP, Best's PAM and Flege's SLM. Specifically, Natural Phonology would claim that Western speakers are hampered by the natural phonetic constraints that their native dialect has imposed on them in relation to voiceless alveolar fricatives. The NP analysis would be that Western listeners have a phonological process that specifies that all voiceless alveolar fricatives must be [+apical]. Even if they have learned to perceive and pronounce the $/ \mathrm{S} /-/ \mathrm{S} /$ distinction to some degree, this phonological process has not been fully deactivated, leading to inconsistent discrimination. In $\mathrm{NP}$, processes can only be inhibited, rather than completely suppressed, and processes that remain active govern, among other things, one's native accent (Donegan \& Stampe, 2009). PAM would consider the critical case as a category goodness assimilation contrast (Best, 1995; Best \& Tyler, 2007) in which Western speakers treat the (non-native) laminal /s/ phoneme as a deviant phone of their native apical sound. In contrast, the Standard Basque /S/ sound can be considered a better fitting phone for their native apical phoneme. In these cases, PAM predicts that learners might achieve some discriminability of the non-native phones, but this will depend on how far they locate the deviant phone from their native one. SLM predicts that a new phonemic category 
will be built for a non-native sound that phonetically differs from the closest L1 phoneme, as long as the listener perceives some acoustic difference between them. The newly established category would not necessarily be the same as the phone built by a native speaker; it might differ in some specific features, or feature weightings (Flege, Munro, \& MacKay, 1995). From all three theoretical perspectives, a bilingual's native dialect causes some difficulty with a non-native dialectal contrast, just as a native language interferes with processing a non-native contrast. As Dufour et al. (2007) suggested, simple exposure to a dialect is not sufficient to overcome the challenge presented by a contrast when one's own dialect has merged this contrast, even in a relatively simple discrimination situation.

\section{Experiment 2: Auditory Lexical Decision Task}

A central question of the current study is how discrimination capacity impacts word recognition. We address this question by measuring how much the two types of bilinguals are affected by phonetic variation during lexical access. There are relatively few studies looking at the cost of regional accents in word recognition. The few studies that have investigated processing costs caused by within-language accents have found that unfamiliar regional accents initially slow down the identification of target words in continuous speech (Floccia et al., 2009; Floccia et al., 2006).

Evans and Iverson (2004) first showed that adaptation to regional accents depends on the native dialect of the listeners. Listening to regional accents of British English, native English speakers normalized their vowel categorizations differently depending on their native dialect and the target accent. Thus, listeners from the south versus the north of England, who had distinct linguistic experiences, did not equally adjust to certain accents of British English. Based on this pattern, our prediction is that a listener's native dialect of Basque will affect perception of the /s//s/ distinction at the lexical level. Given that in Experiment 1 Standard and Western speakers performed significantly differently in discriminating the critical contrast, we expect Western speakers to have difficulties differentiating the apical and laminal fricatives when these sounds are embedded in words. 
Method

\section{Participants}

The participants were the same as those in Experiment 1:29 native speakers of Standard Basque and 26 native Western speakers.

\section{Stimulus Materials}

We selected 24 Basque words containing the apical/s/ sound (following Basque graphemes, S-words), and 24 words with the laminal/s/ sound (Z-words). The critical S-words and Z-words were comparable in terms of frequency (word frequency per million: S-words: 26.2, Z-words: $39.8, t(23)=0.53, p>.05$ ) and length (number of syllables: both sets had on average 3.96 syllables), based on the EHME database (Landa, Sarasola, \& Salaburu, 2010).

For each set of 24 critical words, we made the same number of nonwords (24 S-nonwords and 24 Z-nonwords) by exchanging one phonetic feature, the feature that differentiates the apical /S/ and laminal /s/ sounds. S-nonwords were made from words that originally contained /s/, replacing that with the apical /S/: e.g., [gi.sar.te.a] 'the society'>*[gi.sar.te.a]. Similarly, the /S/ sound in Basque words was replaced with the laminal/s/, producing Z-nonwords: e.g., [ba.ße.sa] 'the protection' $>*$ [ba.ße.sa]. The S-nonwords correspond to the Western dialect merger, while the Z-nonwords are not directly linked to any widespread dialect. Therefore, we consider Znonwords "unlicensed" in terms of Basque dialectal characteristics. 'Accented variants' will refer to utterances that contain the $\mathrm{S}$ sound replacing the $\mathrm{Z}$ sound. In order to be considered full Western variants, these utterances would require further phonological and morphological changes beyond the fricative merger. 'Accented variants' rather than full Western variants were chosen for this task as an abstraction of dialectal characteristics - to see how much perceptual accommodation is evoked by a single dialectal feature. The stimuli were recorded by a native speaker of Standard Basque; critical nonwords were pronounced by having the speaker replace the original fricative in the standard word with the contrasting segment (i.e., $\mathrm{S}>\mathrm{Z}$, or $\mathrm{Z}>\mathrm{S}$ ). In acoustic measurements of the S-words vs. Z-nonwords and the Z-words vs. S-nonwords the apical sounds were louder and had a lower frequency spectral centroid than the laminal sounds. Duration did not reliably distinguish the two sounds. 
There were 72 control items, including 24 control words that did not contain $/ \mathrm{s} / \mathrm{or} / \mathrm{s} /$. To balance the number of words (48 in total, 24 critical plus 24 control) and nonwords, we recorded 48 control nonwords the each included a single phonetic feature change, comparable to the /S/-/s/ exchange (e.g., /k/-/g/,/m/-/n/, /p/-/b/, etc); all were contrasts present in both Basque and Spanish. The controls allow us to see whether participants' performance just depends on acoustic-phonetic similarity or if instead, dialect-based changes are less discriminable. If S- and Z-nonwords create similar error patterns to control nonwords, then acoustic-phonetic similarity is the most reasonable driving force. However, if the pattern for S-nonwords differs from the pattern for control nonwords, then perceptual readjustment to the dialect is implicated.

\section{Design and Procedure}

Participants did 12 practice trials that were not included in the analyses. On each trial, participants heard a token and had to decide whether it was a real Basque word or not. The labels 'Nonword' (Ez-hitza) and 'Word' (Hitza) written in Basque were shown on the left and right sides, respectively, of a computer monitor, and subjects pushed one of two buttons to respond.

There were two counterbalanced lists of 120 trials (48 critical, 72 control). The word and nonword version of the same item never appeared in the same list. Half of the participants were tested with each list, with the items for each listener individually randomized. Participants were given up to $2500 \mathrm{~ms}$ to respond, with the next trial beginning $750 \mathrm{~ms}$ after the subject's response (or after the maximum time). The task took about five minutes.

Participants were informed that nonwords would be very similar to real words, and to only accept a word when they did not notice any mispronunciation in it. In addition, to make sure that listeners would not be biased against accepting accented variants as valid words, they were told to accept an item as valid if they found it natural and likely to be heard in casual speech conversations.

\section{Results and Discussion}

Statistical analyses were conducted as in Experiment 1. The base model included Native Dialect (Standard vs. Western), Lexicality (word vs. nonword) and Sound (S, Z and control) as 
fixed factors. To account for possible confounding interactions among these predictors, the model included a 3-way interaction among the fixed factors (Native Dialect X Lexicality X Sound). The reference level was set to the Standard group, word condition and control sound. RTs were measured from the onset of the item. Missing responses (1.1\%) and time-outs (1.6\%) were treated as in Experiment 1. Figure 2 presents the accuracy and reaction time data for the word and nonword stimuli.

Accuracy: As expected, accuracy for words was very good, with $95 \%$ correct report overall, significantly better than for nonwords (71\%) (Intercept: 4.06, SE: 0.41, $\beta$ : -1.49, SE: 0.5, Wald's z: -2.99). Both groups performed significantly worse on the critical nonwords than on control nonwords, with the S sound creating the most difficulty. The Western speakers accepted S-nonwords as valid Basque items over $90 \%$ of the time, and even the Standard speakers did so $78 \%$ of the time. This larger nonword acceptance by the Western group produced a significant three-way interaction of Native Dialect by Lexicality by Sound ( $\beta$ : -2.21 , SE: 0.76 , Wald's z: 2.91). The strong tendency to accept S-nonwords is due to listeners' perceptual accommodation of accented variants. In fact, this is not an error in the sense that these nonwords are valid items in the Western accent (but not in Standard Basque, even though the Standard group accepted these as words almost $80 \%$ of the time).

This caveat does not apply to Z-nonwords, given that there is no dialectal basis for these items. Despite these being unlicensed forms, Western speakers accepted them $59 \%$ of the time; speakers of Standard Basque did so only $22 \%$ of the time. This pattern produced a significant three-way interaction of Native Dialect by Lexicality by Sound due to the poorer performance by Western speakers ( $\beta$ : -3.54, SE: 0.8, Wald's z: -4.44). Even though the acceptance rate of Znonwords was lower than for S-nonwords, it was still considerably higher than for control nonwords (on average $9.4 \%$ ).

Response Times: Incorrect trials (19\%) were excluded from the reaction time analyses. Both groups show very similar RT patterns in word recognition, with good accuracy associated with fast responses. Overall, both Standard and Western speakers showed significantly faster responses for words (982ms) than nonwords (1110ms) (Intercept: 931.3, SE: 25.9, $\beta$ : 183.33, SE: 25.53, t: 7.18). There was a general cost for the critical sounds over the controls: control words (936ms) were recognized faster than Z-words (1006ms) and S-words (1050ms). This was also the case for nonwords: control items (1085ms) were followed by Z-nonwords (1207ms) and S- 
nonwords (1305ms). The longer responses for the critical sounds in comparison to control sounds yielded significant effects of Sound: S sound ( $\beta$ : 120.67, SE: $25.39, \mathrm{t}: 4.75)$ and Z sound ( $\beta$ : 65.2, SE: 25.38, t: 2.57). There was also a significant interaction of Native Dialect by Lexicality by Sound, due to the longer responses by Western speakers to Z-nonwords ( $\beta$ : 171.55 SE: 31.3, t: 5.48). In combination with the poorer accuracy results, this suggests that these items are especially hard for Western speakers.

\section{INSERT FIGURE 2 HERE}

A critical question is whether there is a latency cost for perceptual adjustment to a dialect. Figure 3 presents the data that bear on this question. Two comparisons are of interest: reaction time differences for recognizing standard variants (Z-words) versus accented variants (Snonwords), and reaction time differences on accepting accented ( $\mathrm{S}$-nonwords) versus unlicensed variants (Z-nonwords). The three stimulus types produced consistent responses across the two groups: accented variants were recognized more slowly than standard words, but faster than unlicensed variants. Even Western speakers recognized standard items faster than the accented variants that are closer to their own productions. This pattern is consistent with the results of Sumner and Samuel (2009), who found an advantage for the standard form, even for dialect speakers. The slower reaction times for Z-nonwords indicate that when bilinguals incorrectly accept them, this is a harder decision that requires more time.

INSERT FIGURE 3 HERE 
Because we used a within-subject design in which we tested participants' performance at the phonetic-phonological level (Experiment 1) and at the level of lexical access (Experiment 2), we can measure whether the acceptance of critical nonwords was correlated with the discrimination capacity shown at the phonetic level. As Figure 4 shows, a strong negative correlation was found for both groups regarding the acceptance of Z-nonwords: Standard speakers: $r=-0.69, p<.001$; Western speakers: $r=-0.56, p<.001$. The worse the accuracy distinguishing /s/ and /s/ on the AXB discrimination task, the more listeners accepted Znonwords as valid Basque utterances. Recall that the percentage of Z-nonword acceptance in Western speakers (59\%) was much higher than that of the Standard Basque speakers (22\%). Western speakers, who had trouble distinguishing the critical Basque contrast at the phonetic level, also have difficulty distinguishing /S/-/s/ exchanges at the lexical level. This makes them accept nonwords that have no accent-based cause, producing chance level acceptance rates for unlicensed variation. This tendency has little to do with perceptual remapping of Basque dialectal variation. The results clearly indicate that difficulties at the phonetic level propagate into difficulties at the lexical level. Together with the discrimination difficulties Western speakers showed at the phonetic-phonological level, the high acceptance of Z-nonwords could reflect an underspecification of the $\mathrm{Z}$ sound in the phonemic inventory of Western speakers. Given that this sound is not part of their native repertoire, these speakers might treat it as an allophone of their native S sound, leading Z-nonwords to behave as lexical allophones of Swords.

\section{INSERT FIGURE 4 HERE}

Interestingly, there is no such significant correlation between discrimination accuracy and the acceptance of S-nonwords: Standard speakers: $r=0.3, p=.19$; Western speakers: $r=-0.16$, $p=.44$. This divergent pattern of correlations indicates that the capacity to encode phoneticphonological information does not alter the ability to accommodate dialectal variation, as 
opposed to the rejection of unlicensed variation. The results of Experiment 2 thus show a clear dissociation between the processing of nonwords that are dialectally valid versus those that are dialectally unusual or unlicensed.

\section{Experiment 3: Auditory Semantic Priming}

Experiments 1 and 2 have shown that bilinguals' native dialect of Basque affects the way they discriminate the $/ \mathrm{s} /-/ \mathrm{s} /$ contrast at the phonetic level and how they deal with variation during lexical access. To further analyze how lexical processing is affected by regional dialects, the current experiment measures semantic activation caused by accented variants once these have been recognized by the listener. Semantic priming is well suited for this goal, as it reflects the associative strength between concepts in semantic memory (Meyer \& Schvaneveldt, 1971), with faster processing latencies when a word (the target) is related to a concept previously presented (the prime). In Experiment 3 we test whether Basque accented variants (S-nonwords) are as effective as standard items (Z-words) in priming a semantically related word. We investigate how accented utterances are represented in the mental lexicon by different types of bilinguals, measuring if experience with the dialect determines the effectiveness of S-nonwords in creating priming effects.

We include a Context manipulation to modify the likelihood that S-nonwords are treated as accented variants and not as mere mispronunciations. The Context factor had two levels Standard versus Dialect - and was implemented as a between-subjects manipulation. It consisted of recorded instructions that participants heard before the task. These instructions were spoken either in Standard Basque or Western (Dialectal) Basque. Subjects given the Dialectal context receive evidence of the speaker's Western accent, potentially helping these listeners during the experiment itself to interpret the $/ \mathrm{s} />/ \mathrm{S} /$ articulation as the Western merger, rather than as a mispronunciation. If such an interpretation aids lexical access, accented variants in this Context will potentially show larger priming effects.

The current experiment allows us to compare initial encoding (i.e. the phonetic and lexical processes tested in Experiments 1 and 2) with post-access lexical activation. If perceptual remapping to dialectal variation only affects initial encoding, then even Western speakers who 
showed difficulties adjusting to legal versus unlicensed variants in Experiment 2 should show no differential costs once lexical access has been achieved.

\section{Method}

\section{Participants}

The same bilinguals who took part in the previous tests did this task.

\section{Stimulus Materials}

48 associated pairs of Basque words were chosen to create our related prime-target pairs. The related primes were standard Z-words that were semantically associated with the target word: e.g., PRIME: zilarra 'the silver'- TARGET: urrea 'the gold'. For each related primetarget pair, we constructed an unrelated prime-target pair (e.g., aingerua 'the angel' - urrea 'the gold), where the related zilarra and unrelated aingerua primes had the same frequency and no semantic relationship.

Similarly, accented primes were created from the related primes. For a detailed examination of the effects of accented variants, in this task we explicitly compare a) variants containing the $/ \mathrm{s} />/ \mathrm{S} /$ exchange (as before) and b) full Western variants that include the $/ \mathrm{s} />/ \mathrm{S} /$ exchange and additional morphonological changes. The goal is to see whether these two types of variation produce similar activation of semantically related words. Hence, among the 48 accented primes, half contained a single-feature-change to the standard Z-word Related primes (e.g., zilarra > *silarra-urrea 'the gold'). These items are equivalent to S-nonwords used in Experiment 2. The other 24 accented primes included 2-feature-changes that corresponded to full Western variants: e.g., eguskixa, from the standard eguzkia 'the sun'. In this case, an epenthetic consonant is added intervocally $(-i+-a>-i x a)$ together with the dialectal $/ \mathrm{s} />/ \mathrm{S} /$ merger.

Two types of control nonword primes were constructed. Single-phonetic-feature control mispronunciations included exchanges comparable to the merger (e.g., /g/ > /k/, /d/ > /t/, /n/ > $/ \mathrm{m} /, / \mathrm{r} />/ \mathrm{r} /, / \mathrm{e} />/ \mathrm{i} /)$, for example zilarra $>*$ zilara $(/ \mathrm{r} />/ \mathrm{r} /)$ - urrea 'the gold'. 2-featurechange control nonwords were included to match the number of features changed in Western 
variants. Thus, if a Western variant included the fricative merger plus an epenthetic consonant, then the control nonword would contain comparable changes. For instance, for the Western variant eguskixa, the control would have the same epenthetic consonant plus a control feature exchange (e.g., eguzkia > *ekuzkixa: 1$)-i+-a>-i x a, 2) / g />/ \mathrm{k} /$ ). Bigram frequency was considered when creating the control primes, so that the bigrams in these items were as frequent as the ones in real words.

Table 2 provides an example of the single-feature-change trials and an example of the 2feature-change trials.

\section{INSERT TABLE 2 HERE}

In total, there were 48 stimulus sets that included four conditions: Related, Unrelated, Accented and Control Nonword. The primes of the Related, Accented and Control conditions were based on Z-words. Within a stimulus set only primes varied; the target was the same across the four conditions. Four counterbalanced lists were used, with the four types of primes rotated across the lists. This ensured that each target word was presented to a participant only once. All subjects received the same 48 critical targets. The design thus provides a within-subject and within-item measure of priming.

Stimuli were recorded by a native speaker of the Western dialect who, due to her close contact with other Basque regions, was bidialectal (Standard and Western dialects). Her pronunciation was assessed by a phonetician, a native speaker of Standard Basque, who confirmed that she was able to perfectly distinguish the $/ \mathrm{s} /$ and $/ \mathrm{s} /$ sounds when speaking in Standard Basque.

In addition to the 48 critical trials, there were 240 filler trials. The same proportion of nonwords and words were included in prime and target positions of filler and critical trials. Nonwords followed Basque phonotactics but had no meaning. These were included to balance the nonwords included on the critical trials, and to greatly reduce the proportion of related items 
that each listener heard. Among fillers, 120 of the primes were words and 120 were nonwords; similarly, 120 of the targets were words and 120 were nonwords. Each nonword used as a filler was made with a single-phonetic-feature change relative to its counterpart standard word. Primes and targets were randomly combined to create filler trials.

Recall that we introduced a Context manipulation by varying whether pre-experiment instructions were presented in Standard versus Western Basque (the instructions contained no instances of the critical /s/, /s/ sounds). We reinforced the Context manipulation by using different sets of filler items for the two Context cases. Fillers were pronounced in the Western accent for the Dialectal Context, and in the Standard accent for the Standard Context.

\section{Design and Procedure}

The task was an auditory lexical decision test with semantic priming. On each trial, participants heard two tokens and they had to decide whether the second one was a real Basque word or not; the prime-target ISI was 500ms. Subjects were instructed to press one response button when the second item (the target) was a valid Basque word, and a different button when the second item was not a real word. The labels 'Nonword' and 'Word' written in Basque were shown on the left and right sides, respectively, of a computer monitor.

There were four counterbalanced lists of 288 trials (48 critical, 240 filler). The four counterbalanced lists were crossed with the two Contexts, resulting in eight stimulus conditions (4 lists $x 2$ contexts). Participants were randomly assigned to conditions so that there were approximately the same number of subjects per list and context. Trials for each listener were individually randomized. All stimuli were presented using the same equipment as in Experiments 1 and 2. Each trial began 1000ms after the subject's response on the previous trial, with a maximum response time of $2500 \mathrm{~ms}$. The task took approximately 23 minutes.

\section{Results and Discussion}

The central question of Experiment 3 is whether, for each Dialect group, Accented primes are as effective as Related semantic primes, with both types being compared to Unrelated primes. This question was addressed using the same statistical analysis approach as in 
Experiments 1 and 2. Both accuracy and RTs were analyzed. The base model included Native Dialect (Standard vs. Western), Priming Condition (with six levels: Related, Unrelated, Accented_1-feature change, Accented_2-feature change, Control Nonword_1-feature change, Control Nonword_2-feature change) and Context (Standard vs. Dialect) as fixed factors, with the interaction of Native Dialect by Context also included. The reference level was set to the Standard group, the Unrelated condition and the Standard Context.

Participants with accuracy lower than $85 \%$ on the lexical decision task were not included in the analyses, eliminating one subject from the Standard group and one from the Western group. This left 28 subjects in the Standard group and 25 subjects in the Western group. Missing responses $(0.4 \%)$ and time-outs $(0.9 \%)$ were treated as in Experiments 1 and 2. Figure 5 shows the accuracy and reaction time results, and Table 3 shows the corresponding priming effects.

INSERT FIGURE 5 HERE

INSERT TABLE 3 HERE

Accuracy: Overall, there were no systematic differences in accuracy across conditions. Performance was consistently very high; all conditions were above $97 \%$ correct on average, leading to a non-significant effect of condition (comparing all the conditions of interest to the Unrelated case, all the $\mathrm{z}$ values were between 1.2 and 0.3 ). Accuracy was slightly better in the Dialectal context, producing a marginal effect of Context (Intercept: 11.47, SE: 3.61, $\beta$ : 4.55, SE: 2.44, Wald's z: 1.88). The interaction of Native Dialect by Context was marginal as well (Intercept: 5.43, SE: 0.96, $\beta$ : -1.48, SE: 0.76, Wald's z: -1.93), driven by the slightly lower performance of the Standard group on the Standard context. 
Response Times: Incorrect trials $(1.6 \%)$ were not included in the reaction time analyses. Performance by the two groups was generally quite similar, as the non-significant effect of Native Dialect reflects (Intercept: 935.89, SE: 38.35, $\beta$ : -1.76, SE: 51.46, t: -0.03, n.s.). The nonsignificant effect of Context ( $\beta$ : -21.68, SE: 48.68 , t: -0.45 , n.s.) demonstrates that priming did not differ across the Standard and Dialectal contexts, contrary to our expectations. The interaction of Native Dialect by Context was not significant either; the Dialect context did not even help Western speakers to recognize the target items faster $(\beta: 63.25$, SE: $70.79, \mathrm{t}: 0.89$, n.s.).

Using the Unrelated case as a baseline, different priming conditions led to different results. There was a significant effect for the Related condition ( $\beta$ : -55.26 , SE: 20.58, t: -2.69$)$, as well as for those that minimally diverged from it: there was significant priming for both the 1feature Accented condition ( $\beta$ : -62.9, SE: 25.17, t: 2.5) and the 1-feature Control Nonword case ( $\beta$ : -65.64, SE: $25.19, \mathrm{t}:-2.61)$. In contrast, those conditions with two features changed did not produce significantly more priming than that in the Unrelated condition ( $\mathrm{t}$ values were between 1.5 and -1.3). Overall, both the Standard and Western groups show consistent priming effects for the Related, 1-feature Accented and 1-feature Control Nonwords. In a similar series of priming experiments, Connine, Blasko, and Titone (1993) also found that minimally different pseudowords produced significant priming effects on related targets, but no priming effects were produced by pseudowords made with three features changed.

Recall that when we compared listeners' ability to discriminate the critical contrast at the phonetic level (AXB) with their performance on lexical decision (Experiment 2), we found a negative correlation: the lower the discrimination accuracy, the more listeners accepted unlicensed variants as valid Basque items. Comparable correlation analyses were conducted for the semantic priming task: We measured whether the priming effects caused by 1-feature Accented primes correlated with discrimination performance on the critical contrast. Neither group showed a significant correlation between the two tasks (Standard: $r=-0.42, p=.06$; Western: $r=-0.06, p=.8$ ). Thus, unlike initial lexical access, the priming effects caused by the $S$ nonwords are not driven by listeners' discrimination capacity.

As Table 3 shows, in general there were stronger priming effects for Western speakers than for the Standard speakers. The difference was clearly most pronounced for the 2-featurechange primes: The Western speakers showed similar priming effects for 1- and 2-feature- 
change Accented variants, while 2-feature Accented variants were not effective primes for Standard speakers. Given that these changes are aspects of the Western dialect, these variants are natural and common utterances for the Western speakers. As a result, words with such changes are effective in a semantic priming task. It appears that the Standard speakers can accommodate the apical-laminal variation, but not more.

If we compare the Western speakers' results to the results for speakers of a New York City dialect in the Sumner and Samuel (2009) study, there are some clear similarities and dissimilarities. Western listeners accepted both standard dialectal variants, much as New York (NY) dialect speakers did in immediate processing tasks (i.e., form and semantic priming) for variants in the standard General American (GA) dialect. The authors suggested that this could be due to the influence of formal learning, media, etc. In contrast, GA listeners (analogous to the Standard Basque group here) treated dialectal variants more like nonwords. Unlike this pattern, we found a significant priming effect for dialectal primes with native speakers of Standard Basque as well. The greater acceptance of dialectal variation for the Basque case may reflect the greater familiarity of Standard Basque speakers with Western Basque speakers. One very interesting feature of the Sumner and Samuel (2009) study is an analysis of the stored form in lexical memory. By using long-term repetition priming, they confirmed that there was a benefit for General American (Standard American English) primes in the long term, even for NY dialect speakers. The results in Sumner and Samuel (2005) are also consistent with this finding: In the long-term there is an advantage for canonical (standard) forms.

\section{General Discussion}

The results of this study demonstrate that not only the native language, but also the dialect one speaks from birth, will determine the way phonemic contrasts are perceived and lexical entries are accessed. In particular, the observed effects shed light on regional accent normalization. The results demonstrate where processing costs arise for accommodating dialectal variation, and where they do not.

To be a native speaker of the Western dialect in principle means to have one phonemic contrast fewer than non-merging Basque speakers do for sibilants. Consequently, as the accuracy 
results of the discrimination task show, Western speakers do not distinguish the /s/ and /s/ sounds as they do control sounds. The lower accuracy and longer RTs for the critical sounds are a clear reflection of the increased difficulty with the phonemic contrast of interest. For Western speakers, exposure to a dialect (through media, school, etc.) that contains the /s/-/s/ distinction has not been enough to support full discrimination of the contrast. Instead, perception is dominated by the native variant, making the /s/ sound non-native like.

Phonemic discrimination difficulties potentially may have an impact on word recognition, and this is exactly what the lexical decision results show for Western speakers. Even though both groups show largely identical patterns for recognizing words, there are critical differences in the acceptance of nonwords. The perceptual difficulties Western speakers had at the phonetic-phonological level led them to accept as words utterances that contained not only legal, but also unlicensed dialectal variation. Western speakers accepted S-nonwords $91 \%$ of the time and Z-nonwords 59\% of the time. The acceptance of the unlicensed Z-nonword variants is the most striking consequence of dialectal differences, given that Western speakers accepted them as valid words more than twice as often as Standard speakers did (22\%). Hence, the influence of the native dialect is crucial at the lexical level: it creates spurious activation of variants with no dialectal basis.

Our two different methods of probing the lexicon showed that there is an important distinction between lexical access and the processing that occurs after initial word recognition: In most cases, the semantic association caused by accented words did not show any effect of the native dialect of Basque. In fact, Standard and Western speakers showed extremely similar priming patterns for the Related, 1-feature Accented and 1-feature Control primes. The Western speakers did tend to show stronger effects, with a robust difference for the 2-feature Accented case, the condition that best matched the dialectal variation. The general tendency of listeners in this task seems to be to respond based on acoustic-phonetic similarity; nonwords with one feature mispronunciation generate the same priming effect as Related words do (Connine et al., 1993), regardless of whether they are dialectally valid or not. These results demonstrate that contrary to the differences we found in lexical access, once lexical items have been activated, minimally differing variants are equally effective in the semantic associations they produce. Our primary theoretical question is where regional accents affect processing, and our results demonstrate that a bilingual's native dialect determines one key aspect of lexical access: 
the listener's willingness to accept or reject variation. Western speakers are much more prone to ignore variation when dealing with the critical $/ \mathrm{s} /$ and $/ \mathrm{S} /$ sounds. This could be due to the fact they experience so much phonetic variation in how these sounds are realized across speakers of their own dialect versus speakers of more standard varieties.

The findings of current study also revealed intriguing parallels in the speech processing of Western speakers and Spanish-Basque late bilinguals (in Larraza et al., submitted). Western speakers are native speakers of Basque; this is their dominant language and they use it most of the time $(65 \%)$ on a daily basis. In contrast, the late bilinguals did not start learning Basque until they were 7 years old, and they only use Basque about $23 \%$ of the time. Given these differences, it is quite interesting that the groups performed equivalently in the discrimination of the Basque critical contrast: Western speakers achieved $86 \%$ accuracy and late bilinguals $86.4 \%$. It appears that the perceptual cost imposed by the native dialect on phonemic discrimination is similar to the native language. In both cases listeners are dealing with a non-native contrast.

Phonemic discrimination difficulties also had a similar effect on the two groups when dealing with variation at the lexical level. Both Western and Spanish-Basque late bilinguals were willing to regularly (over half the time) accept variation that has no dialectal basis. In spite of the distinct profiles of these listeners, both groups were able to associate accented variants with semantically related words. Once the lexical entry has been accessed, minimal variation does not alter the semantic properties of that unit stored in memory. Hence, listeners' lexical knowledge may allow phonetic variants to be automatically matched with their standard counterparts in such a way that semantic association still takes place.

Native speakers of Standard Basque represent the /s/ and /s/ sounds as two separate phonemes. Due to their experience with dialectal variation, for these listeners the apical sound can also act as an allophone of the laminal phoneme in word recognition. In contrast, for Western speakers only the apical /s/ sound constitutes a phoneme, and our results indicate that for these listeners the laminal variant is an allophone in terms of lexical access. Thus, depending on the native dialect and language, the same physical-acoustic pronunciation might be considered a separate phoneme or an unnoticeable allophone. Different experiences with varied pronunciations causes Standard Basque and Western speakers to have different mappings of the phonetic input they hear to their underlying abstract phonological and lexical representations. Our results offer further evidence that phonetic implementation gets established as the language 
is acquired. Flexibility in processing variable forms is not a given, but instead, is enabled by experience with variation (Sumner \& Samuel, 2009). In this sense, exposure to regional varieties helps to establish the match between the phonemically distinct units and all of their phonetic occurrences.

The commonalities in the results for Western speakers and Spanish-Basque late bilinguals show different dimensions of the effect of native listening and provide an explicit comparison of native language versus native dialect effects. The results demonstrate that a nonnative dialect and a non-native language can have similar perceptual consequences in a listener's accepting or rejecting phonetic variation. Thus, it might be more appropriate to think of the native influence within a gradable dimension (Cutler, 2012). Within such a theoretical framework, it still is essential to localize the processing points where these graded effects appear, and the current study has provided new evidence for these loci. 


\section{References}

Barr, D., Levy, R., Scheepers, C., \& Tily, H. J. (2013). Random effects structure for confirmatory hypothesis testing: Keep it maximal. Journal of Memory and Language, 68(3), 255-278.

Bates, D., Maechler, M., Bolker, B., \& Walker, S. (2013). Linear mixed-effects models using Eigen and S4. R package version: 1.0-5. from http://cran.rproject.org/package=Ime4

Best, C. T. (1995). A direct realist view of cross-language speech perception. Speech perception and linguistic experience: Issues in cross-language research, 171-204.

Best, C. T., \& Tyler, M. D. (2007). Nonnative and second-language speech perception: Commonalities and complementarities. In O. Bohn \& M. J. Munro (Eds.), Language experience in second language speech learning: In honor of James Emil Flege (pp. 13-34): Amsterdam: John Benjamins Publishing Company.

Brunellière, A., Dufour, S., Nguyen, N., \& Frauenfelder, U. H. (2009). Behavioral and electrophysiological evidence for the impact of regional variation on phoneme perception. Cognition, 111(3), 390396.

Clopper, C., \& Pisoni, D. B. (2004). Some acoustic cues for the perceptual categorization of American English regional dialects. Journal of Phonetics, 32(1), 111-140.

Connine, C. M., Blasko, D. G., \& Titone, D. (1993). Do the beginnings of spoken words have a special status in auditory word recognition? Journal of Memory and Language, 32(2), 193-210.

Conrey, B., Potts, G. F., \& Niedzielski, N. A. (2005). Effects of dialect on merger perception: ERP and behavioral correlates. Brain and Language, 95(3), 435-449.

Cutler, A. (2012). Native listening: The flexibility dimension. Dutch Journal of Applied Linguistics, 1(2), 169-187.

Cutler, A., Smits, R., \& Cooper, N. (2005). Vowel perception: Effects of non-native language vs. nonnative dialect. Speech Communication, 47(1-2), 32-42.

Deelman, T., \& Connine, C. M. (2001). Missing information in spoken word recognition: Nonreleased stop consonants. Journal of Experimental Psychology: Human Perception and Performance, 27(3), 656-663.

Donegan, P., \& Stampe, D. (1979). The Study of Natural Phonology. In D. Dinnsen (Ed.), Current approaches to phonological theory (pp. 126-173): Bloomington: Indiana University Press.

Donegan, P., \& Stampe, D. (2009). Hypotheses of Natural Phonology. Poznan Studies in Contemporary Linguistics, 45 (1), 1-31.

Dufour, S., Brunellière, A., \& Nguyen, N. (2013). To what extent do we hear phonemic contrasts in a nonnative regional variety? Tracking the dynamics of perceptual processing with EEG. $J$ Psycholinguist Res, 1-13.

Dufour, S., Nguyen, N., \& Frauenfelder, U. H. (2007). The perception of phonemic contrasts in a nonnative dialect. J Acoust Soc Am, 121(4), EL131-EL136.

Evans, B., \& Iverson, P. (2004). Vowel normalization for accent: An investigation of best exemplar locations in northern and southern British English sentences. J Acoust Soc Am, 115(1), 352.

Flege, J. E. (1995). Second language speech learning: Theory, findings, and problems. Speech perception and linguistic experience: Issues in cross-language research, 233-277.

Flege, J. E., Munro, M. J., \& MacKay, I. R. (1995). Effects of age of second-language learning on the production of English consonants. Speech Communication, 16(1), 1-26.

Floccia, C., Butler, J., Goslin, J., \& Ellis, L. (2009). Regional and foreign accent processing in English: Can listeners adapt? J Psycholinguist Res, 38(4), 379-412. 
Floccia, C., Goslin, J., Girard, F., \& Konopczynski, G. (2006). Does a regional accent perturb speech processing? Journal of Experimental Psychology: Human Perception and Performance, 32(5), 1276-1293.

Gaskell, M. G., \& Marslen-Wilson, W. D. (1996). Phonological variation and inference in lexical access. Journal of Experimental Psychology: Human Perception and Performance, 22(1), 144.

Gow, D. W. (2001). Assimilation and Anticipation in Continuous Spoken Word Recognition. Journal of Memory and Language, 45(1), 133-159.

Gow, D. W. (2003). Feature parsing: Feature cue mapping in spoken word recognition. Perception \& Psychophysics, 65(4), 575-590.

Ingram, J. C., \& Park, S.-G. (1997). Cross-language vowel perception and production by Japanese and Korean learners of English. Journal of Phonetics, 25(3), 343-370.

Janson, T., \& Schulman, R. (1983). Non-distinctive features and their use. Journal of Linguistics, 19(02), 321-336.

Landa, J., Sarasola, I., \& Salaburu, P. (2010). Euskal Hiztegiaren Maiztasun Egitura (EHME).

Larraza, S. (2009). Acquisition of phonology and Spanish-Basque bilinguals' phonological systems. Proceedings of Colloque Jeunes Chercheurs en Acquisition du Langage, 102-106.

Larraza, S., Samuel, A. G., \& Oñederra, M. L. (submitted). Listening to accented speech in a second language: First language and age of acquisition effects.

LoCasto, P. C., \& Connine, C. M. (2002). Rule-governed missing information in spoken word recognition: Schwa vowel deletion. Perception \& Psychophysics, 64(2), 208-219.

McLennan, C. T., Luce, P. A., \& Charles-Luce, J. (2003). Representation of lexical form. Journal of Experimental Psychology: Learning, Memory, and Cognition, 29(4), 539-553.

Meyer, D. E., \& Schvaneveldt, R. W. (1971). Facilitation in recognizing pairs of words: evidence of a dependence between retrieval operations. Journal of experimental psychology, 90(2), 227-234.

Mitterer, H., \& Blomert, L. (2003). Coping with phonological assimilation in speech perception: Evidence for early compensation. Perception \& Psychophysics, 65(6), 956-969.

R Development Core Team. (2012). R: A language and environment for statistical computing. Vienna, Austria: R Foundation for Statistical Computing.

Scott, D. R., \& Cutler, A. (1984). Segmental phonology and the perception of syntactic structure. Journal of Verbal Learning and Verbal Behavior, 23(4), 450-466.

Stampe, D. (1979). A dissertation on natural phonology: Garland New York.

Sumner, M., \& Samuel, A. G. (2005). Perception and representation of regular variation: The case of final /t/. Journal of Memory and Language, 52(3), 322-338.

Sumner, M., \& Samuel, A. G. (2009). The effect of experience on the perception and representation of dialect variants. Journal of Memory and Language, 60(4), 487-501. 


\section{FIGURE CAPTIONS}

\section{FIGURE 1}

Accuracy and reaction time results for the AXB task by Spanish-Basque bilinguals with different native dialects of Basque. The error bars in this Figure and in all other Figures represent $95 \%$ confidence intervals.

\section{FIGURE 2}

Accuracy and reaction time results for words and nonwords in the LDT by Spanish-Basque bilinguals with different native dialects of Basque. Note that the left panel below shows the percentage of nonwords that were taken as valid Basque utterances, showing that the two groups systematically accepted S-nonwords.

\section{FIGURE 3}

Reaction time results for the different stimulus types used in the LDT task. Two comparisons of interest are included: Z-words versus S-nonwords, and S-nonwords versus Z-nonwords, in order to see how licensed and unlicensed dialectal variation is accommodated. Recall that results plotted in the 'S-nonword' and 'Z-nonword' bars correspond to nonwords that were accepted as valid Basque utterances. These data complement the results shown in Figure 3, in which only correct trials (i.e., rejected nonwords) were included.

\section{FIGURE 4}

Correlation between the accuracy on the critical contrast discrimination (AXB task) and the acceptance of Z-nonwords (LDT), by native speakers of Standard Basque and Western dialect.

\section{FIGURE 5}


Accuracy and reaction time results for the Auditory Semantic Priming task by Spanish-Basque bilinguals with different native dialects of Basque. The solid line corresponds to the Related condition and the dotted line to the Unrelated condition. The results of the two Contexts (Standard vs Dialectal) are collapsed due to the very weak effect showed of that factor.

\section{TABLE 1}

Phonemic distribution of the apico- and lamino-alveolar voiceless fricatives across the languages of interest (i.e., Basque, Spanish), taking Basque dialects into account. Corresponding graphemes for the Basque sounds are given in quotations.

\section{TABLE 2}

Examples of 1-feature-change and 2-feature-change trials used in the Auditory Semantic Priming experiment. Phonetic features that change in Accented and Control conditions relative to the Related condition are in bold.

\section{TABLE 3}

Semantic priming effects, based on reaction times, for the two participant groups across the four experimental conditions. The results of the Standard and Dialectal contexts are collapsed due to the very weak effect of that factor. 
FIGURE 1

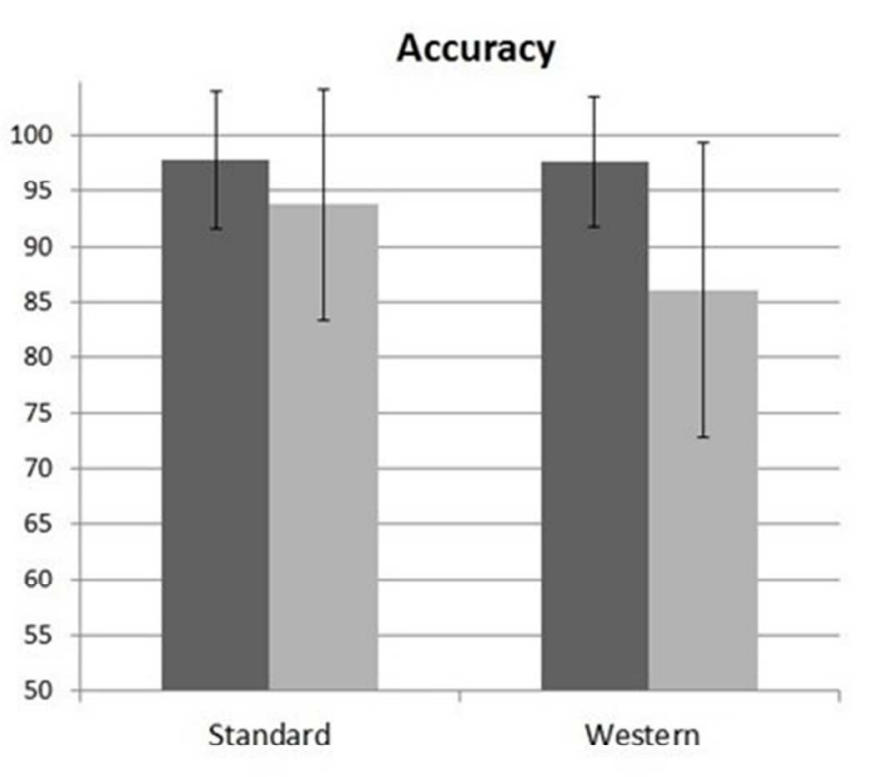

AXB task

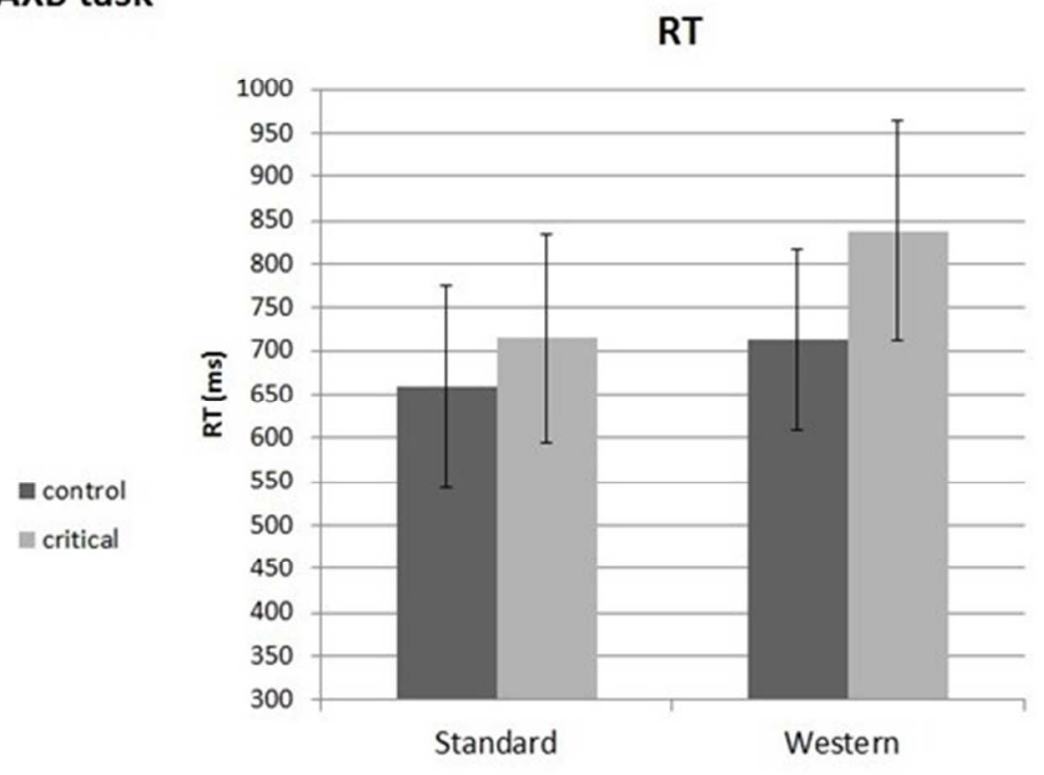


FIGURE 2
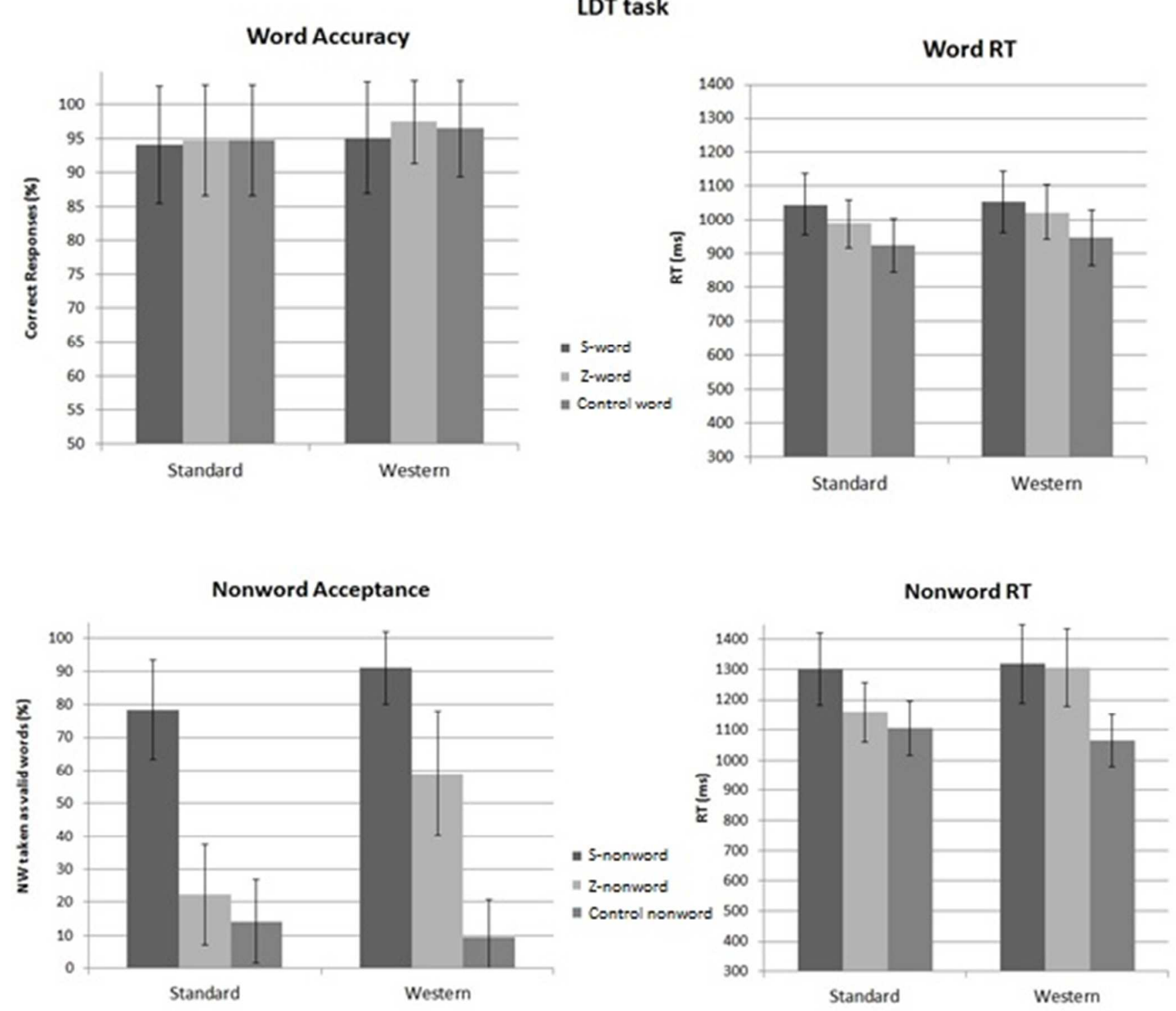

URL: http:/mc.manuscriptcentral.com/pqje 
FIGURE 3

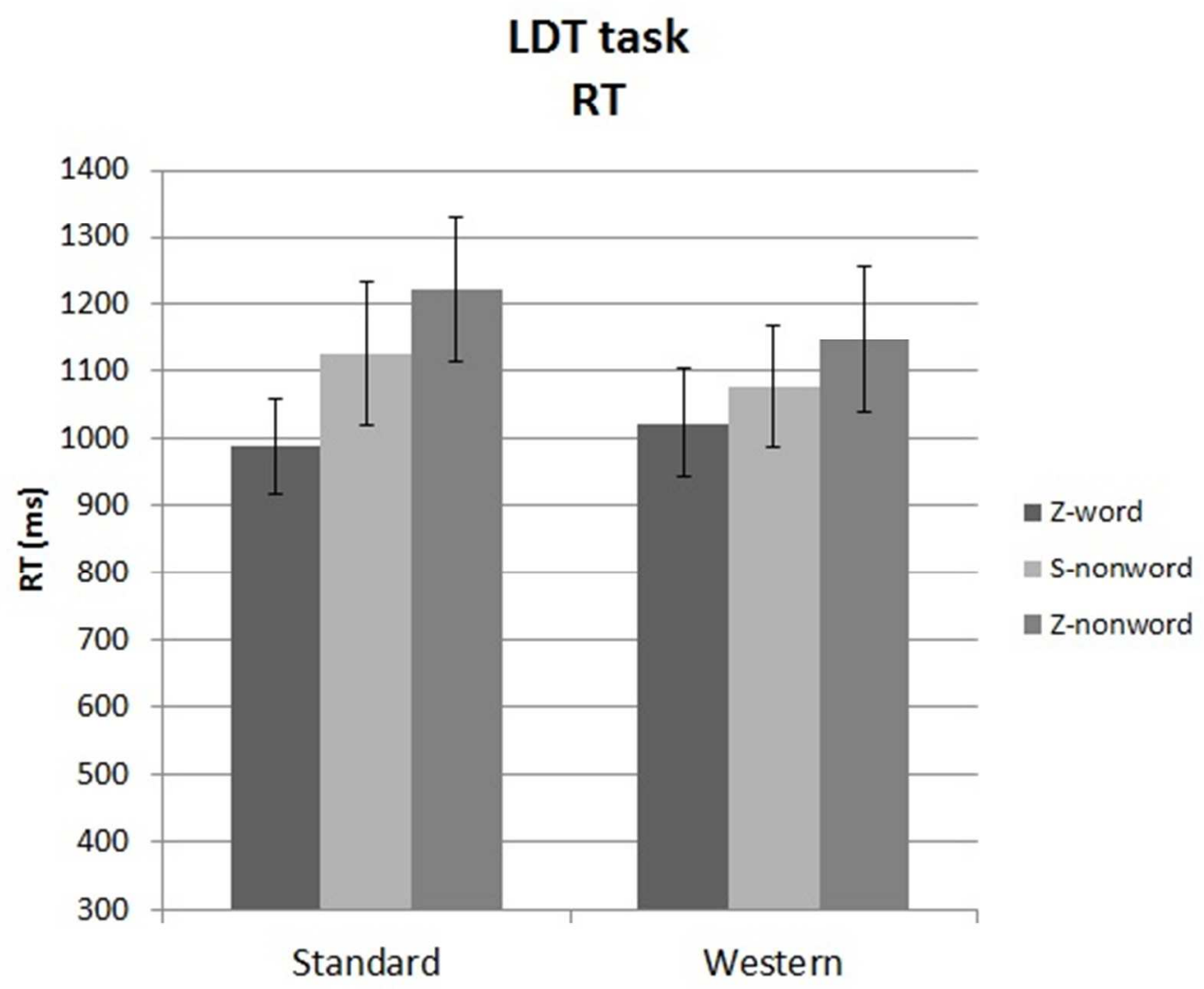

URL: http:/mc.manuscriptcentral.com/pqje 
FIGURE 4

5

6

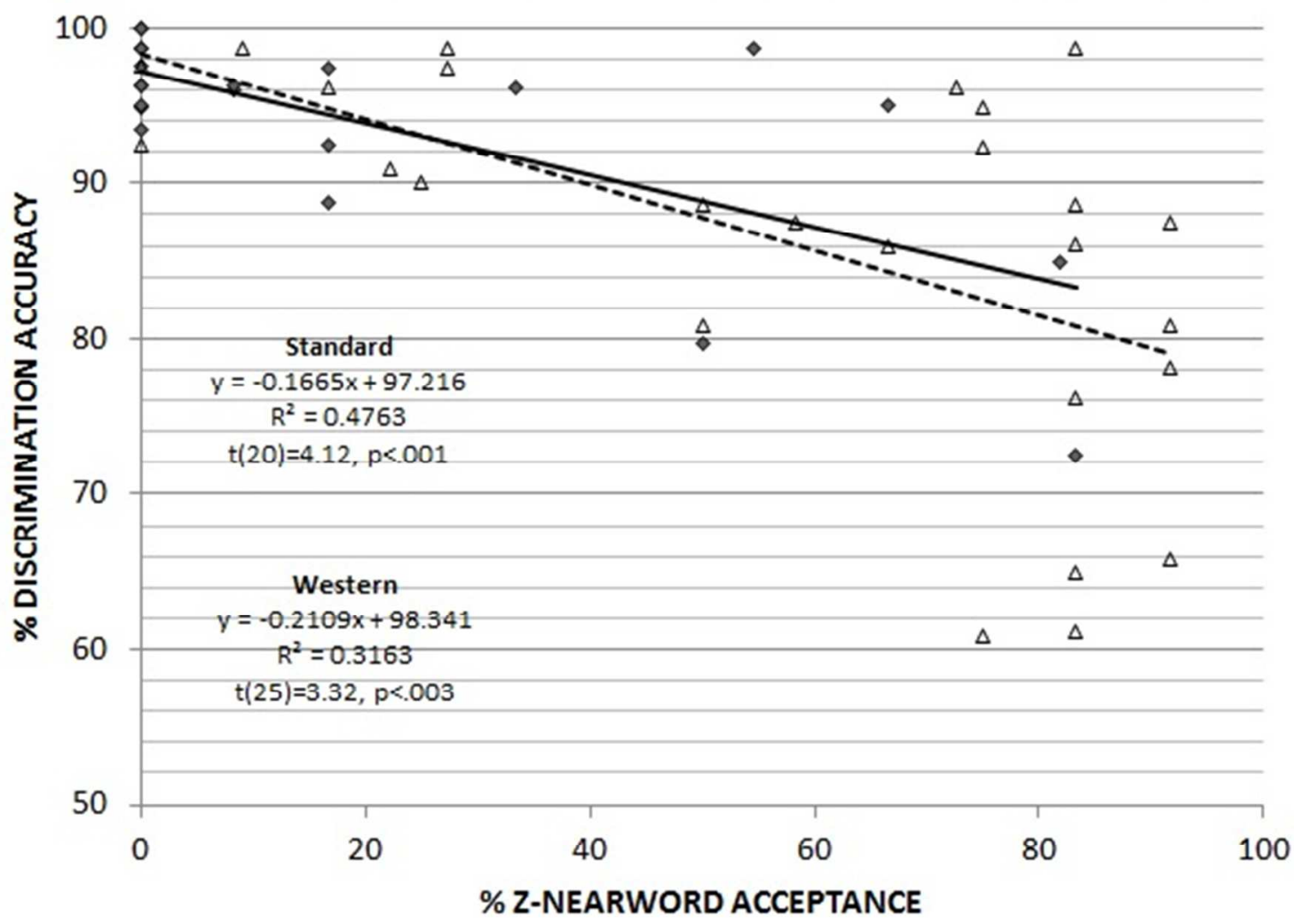

- Standard

$\Delta$ Western

Line ar (Standard)

--.-. Linear (Western) 
FIGURE 5

Accuracy

8

\section{9} 10100

11

12

13

13
14

施

10

18

109

20

22

23

24

25

26

27

28

29

30

31

32

33

34

35

36

37

38

39

40

41

42

43

44

45

46

47

48

49

50

51

52

53

54

55

56

57

58

59

60

\section{Priming task}

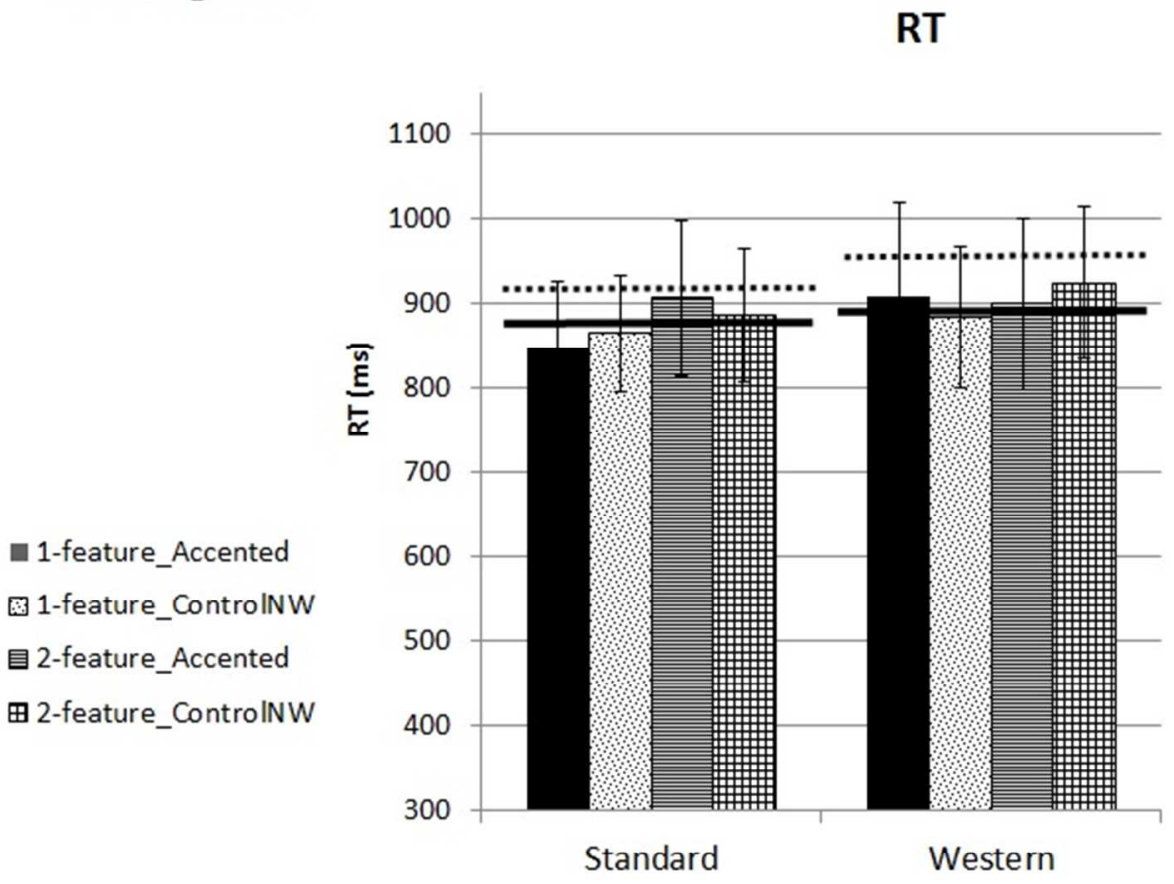


1

2

3

4

5

6

7

8

9

10

11

12

13

14

15

16

17

18

19

20

21

22

23

24

25

26

27

28

29

30

31

32

33

34

35

36

37

38

39

40

41

42

43

44

45

46

47

48

49

50

51

52

53

54

55

56

57

58

59

60

TABLE 1

\begin{tabular}{|c|c|c|c|}
\hline & \multicolumn{2}{|c|}{ Basque } & Castilian \\
\hline & $\begin{array}{c}\text { Standard } \\
\text { dialect }\end{array}$ & $\begin{array}{c}\text { Western } \\
\text { dialect }\end{array}$ & Spanish \\
\hline $\begin{array}{c}\text { Apico-alveolar } \\
\text { fricative }\end{array}$ & $\begin{array}{l}/ \mathbf{S} / \\
66 "\end{array}$ & & $/ \mathbf{S} /$ \\
\hline $\begin{array}{c}\text { Lamino-alveolar } \\
\text { fricative }\end{array}$ & $\begin{array}{l}/ \mathbf{S} / \\
\text { "6"z" }\end{array}$ & $/ \mathbf{S} /$ & - \\
\hline
\end{tabular}


TABLE 2

\begin{tabular}{|l|c|c|c|c|}
\hline \multirow{2}{*}{ CONDITION } & \multicolumn{2}{|c|}{ single-feature-change } & \multicolumn{2}{c|}{ 2-feature-change } \\
\cline { 3 - 6 } & PRIME & TARGET & PRIME & TARGET \\
\hline 1. Related & $\begin{array}{c}\text { zilarra } \\
\text { 'the silver' }\end{array}$ & eguzkia & \\
2. Unrelated & aingerua & & iraultza & uda \\
3. Accented & 'the angel' & urrea & 'the revolution' & 'the summer' \\
4. Contern variant) & *silarra & 'the gold' & *eguskixa & \\
\hline
\end{tabular}




\section{TABLE 3}

\begin{tabular}{lcc}
\hline & Priming Effects (ms) & \\
\hline & Standard & Western \\
Related & 41.6 & 70.7 \\
1-feature Accented & 67 & 53.4 \\
1-feature & 50.6 & 77.7 \\
Control Nonword & & \\
2-feature Accented & 8.7 & 62.4 \\
2-feature & 28.3 & 37.4 \\
Control Nonword & & \\
\hline
\end{tabular}

